\title{
Ontogenetic stage-specific reciprocal intraguild predation
}

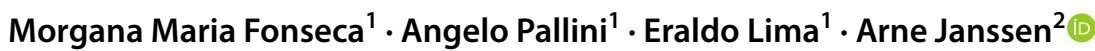

Received: 5 March 2018 / Accepted: 27 August 2018 / Published online: 1 September 2018

(c) The Author(s) 2018

\begin{abstract}
The size or stage of interacting individuals is known to affect the outcome of ecological interactions and can have important consequences for population dynamics. This is also true for intraguild predation (the killing and eating of potential competitors), where the size or ontogenetic stage of an individual determines whether it is the intraguild predator or the intraguild prey. Studying size- or stage-specific interactions is therefore important, but can be challenging in species with complex life histories. Here, we investigated predatory interactions of all feeding stages of the two predatory mite species Neoseiulus californicus and Phytoseiulus macropilis, both of which have complex life cycles, typical for predatory arthropods. Populations of these two species compete for two-spotted spider mites, their prey. We evaluated both the capacity to kill stages of the other predator species and the capacity to benefit from feeding on these stages, both prerequisites for the occurrence of intraguild predation. Ontogeny played a critical role in the occurrence of intraguild predation. Whereas the juveniles of $P$. macropilis developed from larva until adulthood when feeding on $N$. californicus eggs, interestingly, adult female $P$. macropilis did not feed on the smaller stages of the other species. We furthermore show that intraguild predation was reciprocal: both juveniles and adult females of $N$. californicus preyed on the smallest stages of $P$. macropilis. These results suggest that a proper analysis of the interactions between pairs of species involved in intraguild predation should start with an inventory of the interactions among all ontogenetic stages of these species.
\end{abstract}

Keywords Predator-predator interactions $\cdot$ Stage structure $\cdot$ Ontogenetic diet shifts $\cdot$ Predatory mites $\cdot$ Biological control

\section{Introduction}

The type and strength of ecological interactions frequently depend on the the size or stage of the interacting individuals (Werner and Gilliam 1984; Polis and Strong 1996; Rudolf and Lafferty 2011). Because predators often begin their lives

Communicated by Sven Bacher.

Arne Janssen

arne.janssen@uva.nl

Morgana Maria Fonseca

morganamaria.fonseca@gmail.com

Angelo Pallini

pallini@ufv.br

Eraldo Lima

eraldo.lima@ufv.br

1 Department of Entomology, Federal University of Viçosa, Viçosa, Minas Gerais, Brazil

2 Evolutionary and Population Biology, IBED, University of Amsterdam, Science Park 904, 1098 XH Amsterdam, The Netherlands small and vulnerable, this has consequences for their ecological role, for example, they may compete for resources with individuals of another species when small and prey on the same species when large (Wilbur 1988). Moreover, an individual acting as a predator when adult and large may be vulnerable to attacks and be killed by large adult prey when small (Polis et al. 1989; Polis 1991; Palomares and Caro 1999; Janssen et al. 2002) and this can result in complex dynamics (Persson et al. 2007a; Van Leeuwen et al. 2008; de Roos and Persson 2013). Such killing of small predators may arise both within species through cannibalism (Elgar and Crespi 1992) and among species through hyperpredation (Rosenheim 1998), intraguild predation (Polis et al. 1989; Polis 1991; Palomares and Caro 1999), omnivory (Faraji et al. 2001; Janssen et al. 2002, 2003) and, intriguingly, even through predation by prey that are considered purely herbivorous (Aoki et al. 1984; Saito 1986).

Intraguild predation (IGP), the killing and eating of heterospecific competitors, is a widespread interaction (Polis et al. 1989; Arim and Marquet 2004) and has important consequences for population dynamics, species coexistence and 
community structure (Mylius et al. 2001; Woodward and Hildrew 2002; Persson et al. 2007b; Schröder et al. 2009; Montserrat et al. 2012; de Roos and Persson 2013; Preston et al. 2014; Toscano et al. 2016, 2017). Often, the stage or size of the individual determines whether it is an intraguild predator or intraguild prey. This is frequently studied or modelled as large, adult individuals of one species feeding on juveniles of the other species (Polis et al. 1989; Mylius et al. 2001; Woodward and Hildrew 2002; Montserrat et al. 2012). Although this is a good first approximation, interactions among species with complex life cycles may require a further subdivision into interactions between the ontogenetic stages of the involved individuals. For example, first-instar larvae of the thrips species Frankliniella occidentalis are vulnerable to predation by older stages and adults of several species of predatory mites, but second-instar larvae and adults are invulnerable (Bakker and Sabelis 1989; Belliure et al. 2008). Prepupae, the stage between second-instar larvae and pupae, have the size of a full-grown second-instar larva, but are again vulnerable to attacks by the predatory mites (K. Muñoz-Cárdenas and M. Duarte, pers. obs.). In return, both first- and second-instar and adult thrips prey on eggs of the predatory mites (Janssen et al. 2002; de Almeida and Janssen 2013). This shows that both size and stage determine predation risk.

In stage-structured systems, different stages of interacting predatory species often coexist, and two co-occurring predator species may attack each other's vulnerable stages (Polis 1984; Choh et al. 2012; Montserrat et al. 2012; Marques et al. 2018), thus engaging in a more complex type of IGP, termed reciprocal intraguild predation (RIGP), which is also observed in natural systems (Polis et al. 1989; Wissinger 1992; Woodward and Hildrew 2002; Marques et al. 2018). Because of the importance of intraguild predation and reciprocal intraguild predation for population dynamics and species coexistence, it is necessary to investigate the interactions among all stages of species pairs that are suspected to be involved in these interactions. Here, we quantified predation of two predator species by feeding stages of the other species.

Some of the best studied systems with intraguild interactions consist of biological control systems, especially in greenhouse crops, because these artificial food webs (Ehler 1996) are easier to manipulate than natural systems (Messelink et al. 2012). The increased use of biological control agents in agricultural crops has led to a growing complexity of these artificial food webs; hence, the densities of the target pests species are increasingly determined by the joint effects of various direct and indirect interactions among prey and predators (Janssen et al. 1998; Rosenheim et al. 1999; Cakmak et al. 2006; Messelink et al. 2012; van Lenteren et al. 2018). With the presence of several natural enemies, particularly generalist predators, IGP can occur more frequently and is increasingly considered in the development of successful biological control programmes (Rosenheim et al. 1993, 1995, Janssen et al. 1998, 2006; Messelink and Janssen 2014; Wells et al. 2017). Here, we investigated the interplay between ontogenetic stages and IGP interactions in a system consisting of two biological control agents: the predatory mite species Neoseiulus californicus (McGregor) and Phytoseiulus macropilis (Banks), (Acari: Phytoseiidae). Our aim was to evaluate whether these predatory mites interact through intraguild predation and, if so, which stages are involved in this.

\section{Materials and methods}

\section{The experimental system}

The two predatory mites are mass produced in several regions of the world and used as biological control agents of the two-spotted spider mite Tetranychus urticae [Koch (Acari: Tetranychidae)] (McMurtry and Croft 1997; Gerson et al. 2003), which is a cosmopolitan pest of over 1100 plant species and is resistant to many pesticides (Van Leeuwen et al. 2010; Migeon and Dorkeld 2015). In Brazil, both P. macropilis and N. californicus co-occur naturally in extensive regions on various plant species (Ferla et al. 2007; Roggia et al. 2009). Phytoseiulus macropilis is considered a specialist predator of Tetranychus species and tends to disperse from crops when the densities of prey are low (McMurtry and Croft 1997; Oliveira et al. 2007), whereas $N$. californicus has more generalist feeding habits and can thus feed on other food types in periods of low prey densities (Croft et al. 1998; Gerson et al. 2003). Therefore, these predators have been considered for combined releases to control $T$. urticae.

Both predators have five developmental stages: egg, larva, protonymph, deutonymph (the latter three here together referred to as juvenile) and adult. The size of each stage is similar for both species, and the duration of their development from egg to adult is about 5 days for both species (Escudero and Ferragut 2005; Souza-Pimentel et al. 2017). Both protonymphs and deutonymphs need to feed to complete their development and although most predatory mite larvae do not need to feed to reach the next stage, the larvae of our system were observed feeding. We systematically explored intraguild predation by juveniles and adults of the two species and verified whether reciprocal intraguild predation occurred. We evaluated both the capacity to kill stages of the other species as well as the capacity to benefit from feeding on these stages, both of which are prerequisites for the occurrence of IGP (Polis et al. 1989; Fonseca et al. 2017). 


\section{Cultures}

The two-spotted spider mite (T. urticae) was reared on jack bean plants [Canavalia ensiformis (L.) DC] in a climatecontrolled room $\left(25 \pm 3{ }^{\circ} \mathrm{C}, 70-90 \%\right.$ relative humidity, with controlled photoperiod 12:12 L:D). Clean jack bean plants were grown in a greenhouse until they were 2 weeks old and were subsequently added to the spider mite culture twice per week. The predatory mites P. macropilis and $N$. californicus were reared under the same conditions as above on detached bean leaves infested with two-spotted spider mites. These leaves were put in a plastic tray $(l \times w \times h=45 \times 30 \times 8 \mathrm{~cm})$ that was placed inside a second, water-containing tray $(55 \times 40 \times 10 \mathrm{~cm})$ to prevent the mites from escaping. New bean leaves with spider mites were added to the cultures two to three times per week. The cultures of spider mites and predatory mites were started with individuals obtained from cultures from Econtrole Pesquisa \& Consultoria Ltda (Viçosa, MG, Brazil). Both predatory mite species had been reared for about a year on jack bean leaves with two-spotted spider mites prior to the experiments.

\section{Experimental setup}

The experimental units used for all experiments consisted of plastic Petri dishes (diameter $6 \mathrm{~cm}, 1.5 \mathrm{~cm}$ high). Each Petri dish contained a small piece of wet cotton wool as a water source and was closed with cling film (Alpfilm ${ }^{\circledR}$, Alpfilm Indústria e Comércio de Plásticos Ltda, São Paulo, Brazil). All adults used in the experiments were gravid females, aged between 10 and 15 days since the egg stage. These adult females were placed singly in the experimental units and were starved for $24 \mathrm{~h}$ prior to the experiments to prevent possible effects from the previous diet. Only females that had oviposited during this starvation period were used.

Cohorts of newly laid eggs and larvae were obtained by transferring females from the cultures to separate arenas of bean leaves with spider mites and allowing them to lay eggs for $24 \mathrm{~h}$. Subsequently, the eggs were separated on a new arena, and were checked for hatched larvae every $12 \mathrm{~h}$. Preliminary experiments were done to check how many individuals to offer to avoid prey depletion. All experiments were conducted in a climate-controlled room (conditions as above).

\section{IGP of adult females on heterospecific eggs, larvae and adult females}

We first evaluated the predation rate of adult females of both species on heterospecific eggs and larvae and the effect of this feeding on their oviposition rate to verify whether adult females gained from this predation (Polis et al. 1989; Fonseca et al. 2017). A single gravid female was placed in each experimental unit together with eight heterospecific eggs or larvae. To measure natural mortality, only eggs or larvae were placed in another set of arenas. One day later, the deflated eggs or the shrivelled larvae were counted as evidence of predation. All treatments were replicated 14 times for $N$. californicus with eggs and 18 times with larvae of the other species and for $P$. macropilis 28 times with eggs and 27 times with larvae of $N$. californicus.

The oviposition rates of adult females feeding on heterospecific eggs or larvae were measured by offering eight eggs or eight larvae to adult females of the other species. As controls, the oviposition rate of adult females without food was assessed on another set of arenas. Newly laid eggs were counted every $24 \mathrm{~h}$ and the adult females were transferred to new experimental units. The experiments lasted 5 days and were replicated 14 times for $N$. californicus feeding on eggs of P. macropilis, and lasted 4 days and was replicated 10 times for $N$. californicus feeding on larvae of $P$. macropilis. We did not measure oviposition rates for adult females of $P$. macropilis when feeding on eggs or larvae of the other species because the predation experiment showed no evidence of predation.

In another experiment, we investigated whether adult females ate adult females of the other species. One adult female of each species was placed in each experimental unit together with a heterospecific adult female. Individuals of both species were held separately in controls to measure natural mortality. The predation was assessed after $24 \mathrm{~h}$ and the number of replicates was 16 per treatment. This experiment showed no evidence of predation between the adult females and oviposition rates were therefore not measured.

\section{IGP of juveniles on heterospecific eggs and juveniles}

To examine whether other ontogenetic stages were potential intraguild predators, we assessed the predation rates of juveniles of both species on heterospecific eggs and juveniles. To verify whether this predation resulted in a benefit for the predator, we furthermore assessed the development and survival of the juveniles when feeding on heterospecific eggs and juveniles. The first experiment was started by placing a newly hatched larva in each experimental unit together with six heterospecific eggs. To measure natural mortality of eggs and as control for juvenile survival, there were two further treatments: only eggs or only larvae without eggs. Every $24 \mathrm{~h}$, the state (dead or alive) and developmental stage of the juveniles were checked and preyed eggs were counted. Subsequently, the juveniles were transferred to new experimental units with new eggs (without eggs in the treatment with only larvae), and the eggs that were incubated without larvae to assess natural egg mortality were also renewed. The experiments lasted until the juveniles reached adulthood or died. Each treatment was replicated 12 times for 
N. californicus juveniles and 16 times for P. macropilis juveniles.

In another experiment, we investigated whether juveniles ate juveniles of the other species. One newly hatched larva of each species was placed in each experimental unit together with a newly hatched heterospecific larva. Individuals of both species were held separately in controls. The predation and developmental stage of juveniles were assessed every $24 \mathrm{~h}$ and the number of replicates was 14 per treatment. This experiment lasted 2 days, when predators were at the protonymph stage, because the previous experiment showed that more than $60 \%$ of the $P$. macropilis juveniles without food had died on the third day and, thus, we could no longer discriminate between death due to starvation or predation. Therefore, it was not possible to measure intraguild predation among the deutonymphs in this experiment. Moreover, we did not investigate each juvenile stage separately because their duration can vary and may not last a day.

\section{Statistics}

Predation rates were compared with the Wilcoxon rank-sum test. To analyse the effects of feeding on heterospecific eggs on survival of juveniles, we used a time-to-event analysis (Cox proportional hazards model) using the function 'coxph' of the 'survival' package (R Development Core Team 2017). The Kaplan-Meier estimate, which takes censored data into account, was used to assess survival through time. Because none of the juveniles reached the deutonymph or adult stage in the controls, the proportions of juveniles reaching these stages were compared with a Pearson's Chi-squared test. Oviposition rates of adult females were compared between treatments with a Wilcoxon rank-sum test. All analyses were performed with the statistical software R, version 3.3.3 (R Development Core Team 2017).

\section{Results}

\section{IGP of adult females on heterospecific eggs, larvae and adult females}

The mortality of eggs of $N$. californicus in the presence and absence of adult $P$. macropilis was zero. The mortality of $N$. californicus larvae in the presence of adult P. macropilis was low and not significantly different from mortality without adult $P$. macropilis (Fig. 1; Wilcoxon rank-sum test: $W=317, P=0.35)$. We conclude that adults of $P$. macropilis are not intraguild predators of $N$. californicus eggs and larvae.

In contrast, there was a significantly higher mortality of eggs of $P$. macropilis in the presence of adult females of $N$. californicus than in their absence (mortality with $N$.

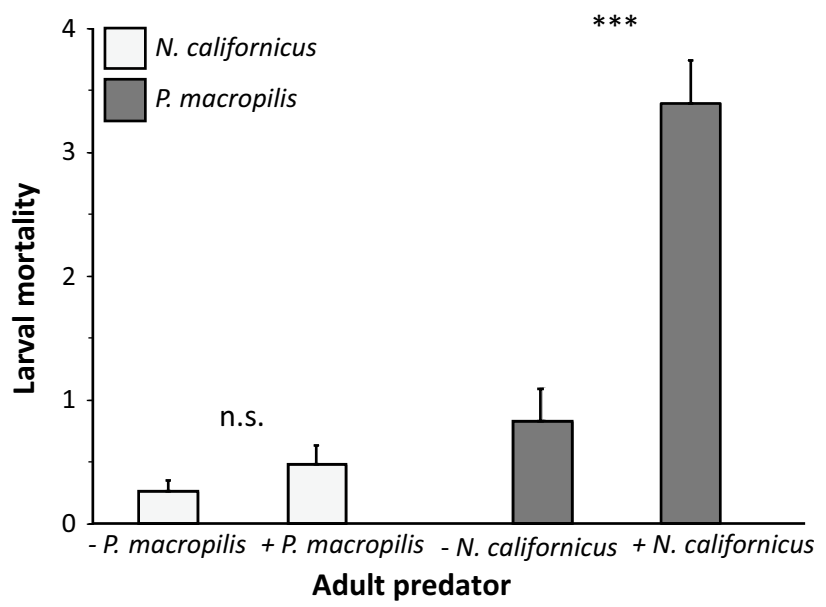

Fig. 1 Average mortality (+SE) of larvae of $N$. californicus (light bars) and P. macropilis (dark bars) after $24 \mathrm{~h}$ in the presence (+) or absence (-) of an adult female of the other species. Asterisks indicate significant effect of the presence of an adult predator on mortality within a larval species. $* * *: P<0.001 ;$ n.s not significant

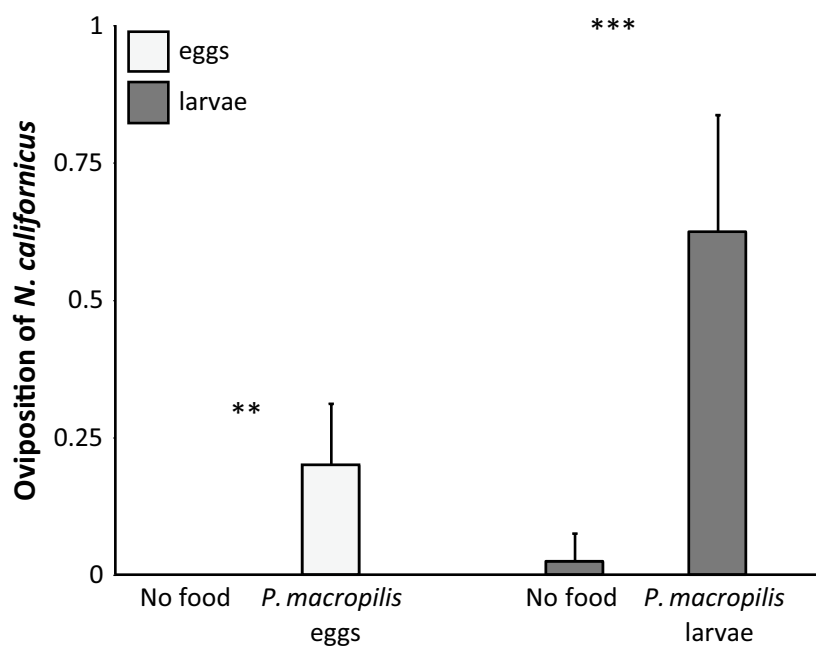

Fig. 2 Average oviposition ( $\pm \mathrm{SE}$ ) of $N$. californicus fed on P. macropilis eggs (during 5 days, light bars) or larvae (during 4 days, dark bars) and without food (No food). Asterisks show significance of difference between the treatment without food and with intraguild prey. **: $P<0.01$; ***: $P<0.001$

californicus: $1.14 \pm 0.44$ (SE) eggs, without $N$. californicus: 0.0 eggs; Wilcoxon rank-sum test: $W=140, P=0.016$ ). The mortality of larvae of $P$. macropilis was also higher in the presence of adult females of $N$. californicus than in their absence (Fig. 1; Wilcoxon rank-sum test: $W=294.5$, $P<0.001)$. Adult females of Neoseiulus californicus did not oviposit in the absence of eggs of P. macropilis, and half of the females of $N$. californicus oviposited in the presence of eggs of $P$. macropilis. This difference was significant (Fig. 2; Wilcoxon rank-sum test: $W=147, P=0.006$ ). All 
adult females of $N$. californicus oviposited in the presence of larvae of $P$. macropilis and only one female produced one egg in their absence, and this difference was also significant (Fig. 2; Wilcoxon rank-sum test: $W=98, P<0.001$ ). We conclude that adult females of $N$. californicus are intraguild predators of $P$. macropilis eggs and larvae.

There was no mortality of adult females in the presence or absence of adult females of the other species.

\section{IGP of juveniles on heterospecific eggs and juveniles}

Juveniles of both $N$. californicus and P. macropilis preyed on eggs of the other species until they reached adulthood (Fig. 3). This resulted in a significant mortality of the eggs ( $P$. macropilis eggs: Wilcoxon rank-sum test: $W=120, P=0.0013 ; N$. californicus eggs: $W=232$, $P<0.001)$. Juvenile survival of both species significantly increased by feeding on heterospecific eggs ( $N$. californicus: Fig. 4a, Cox proportional hazards: $\log$ rank $=6.52$, $d f=1, P=0.011 ;$ P. macropilis: Fig. 4b, Cox proportional hazards: $\log$ rank $=13.3, d f=1, \mathrm{P}=0.0003$ ). In the absence of $P$. macropilis eggs, none of the $N$. californicus juveniles $(n=12)$ reached the deutonymph or adult stage, whereas $58 \%$ reached the deutonymph stage (Pearson $\chi^{2}: 12.3, d f=3$, $P=0.0063$ ) and $33 \%$ reached adulthood (Pearson $\chi^{2}: 13.3$, $d f=3, P=0.0039)$ in their presence. Juveniles of $P$. macropilis $(n=16)$, did not develop into deutonymphs or adults in the absence of $N$. californicus eggs, but $63 \%$ reached the deutonymph stage (Pearson $\chi^{2}: 17, d f=3, P=0.0007$ ) and $44 \%$ adulthood (Pearson $\chi^{2}: 16.3, d f=3, P=0.0010$ ) in their presence. This shows that the juveniles kill heterospecific eggs and benefit from this, which are both prerequisites for

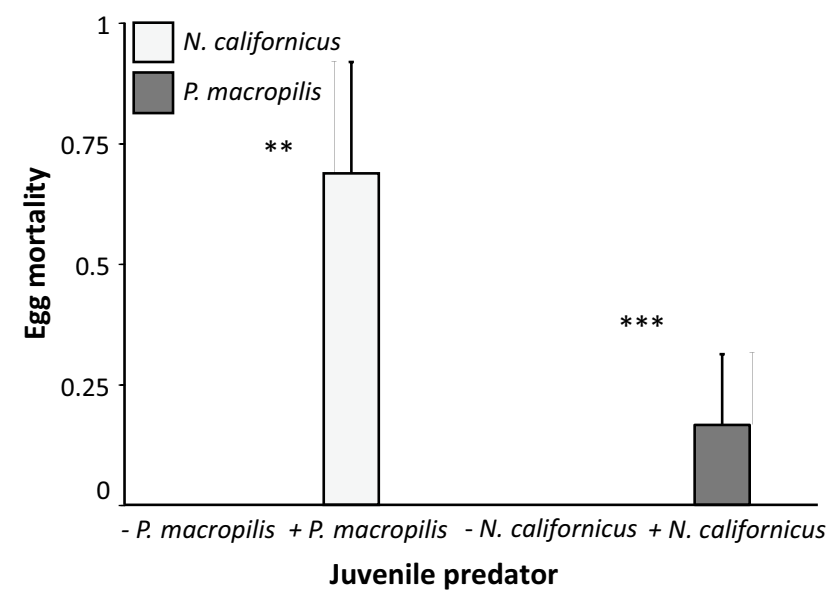

Fig. 3 Average egg mortality (+ SE) of $N$. californicus (light bars) and $P$. macropilis (dark bars) in the presence $(+)$ or absence $(-)$ of juveniles of the other species. Asterisks indicate significant effect of the presence of a juvenile predator on mortality within eggs of a species. **: $P<0.01 ; * * *: P<0.001$ (a) N. californicus

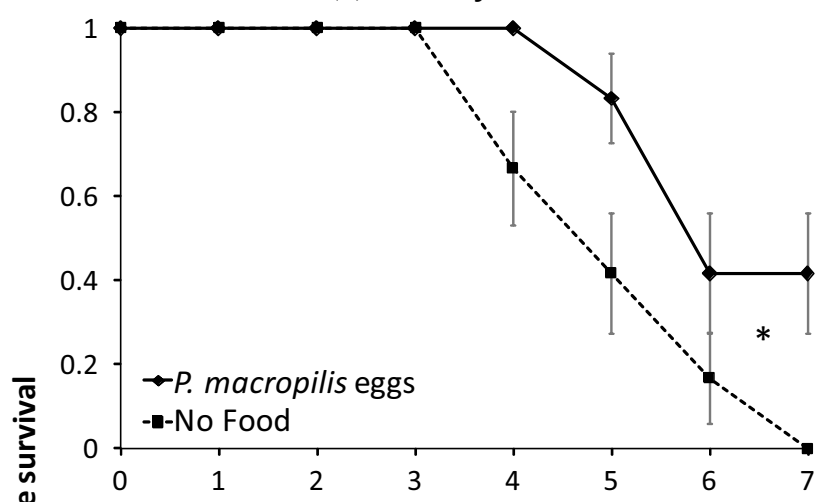

(b) P. macropilis

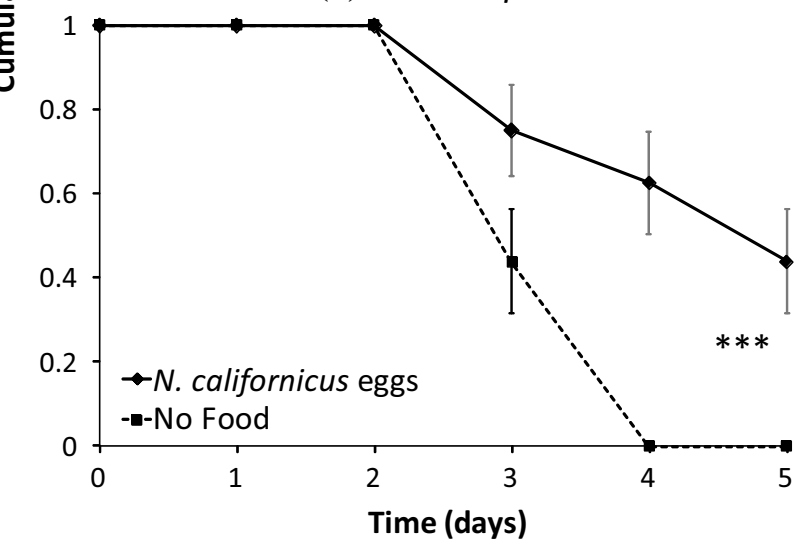

Fig. 4 Cumulative survival $( \pm \mathrm{SE})$ as a function of time of juveniles of $N$. californicus a and P. macropilis, $\mathbf{b}$ fed on heterospecific eggs (diamonds, solid line) and without food (No food, squares, dashed line). Asterisks indicate significance in survival between the two treatments per species. *: $P<0.05 ; * * *: P<0.001$

IGP (Polis et al. 1989; Fonseca et al. 2017). We therefore conclude that juveniles of both species are intraguild predators of heterospecific eggs.

There was no mortality of larvae and protonymphs of the two species in the presence of the same stages of the other species (14 replicates). We conclude that juveniles (larvae and protonymphs) of both species are not intraguild predators of heterospecifics of the same stage.

\section{Discussion}

Our results show that ontogeny clearly plays a critical role in determining the occurrence of intraguild predation (IGP) within our predator system. Figure 5 summarizes the results and shows the complex interactions occurring between these two species. So far, most studies on IGP in arthropods have focused on adult individuals preying on juveniles (but see Guo et al. 2016). In contrast, we show here that juvenile stages can be IG predators but adults are not: whereas the 


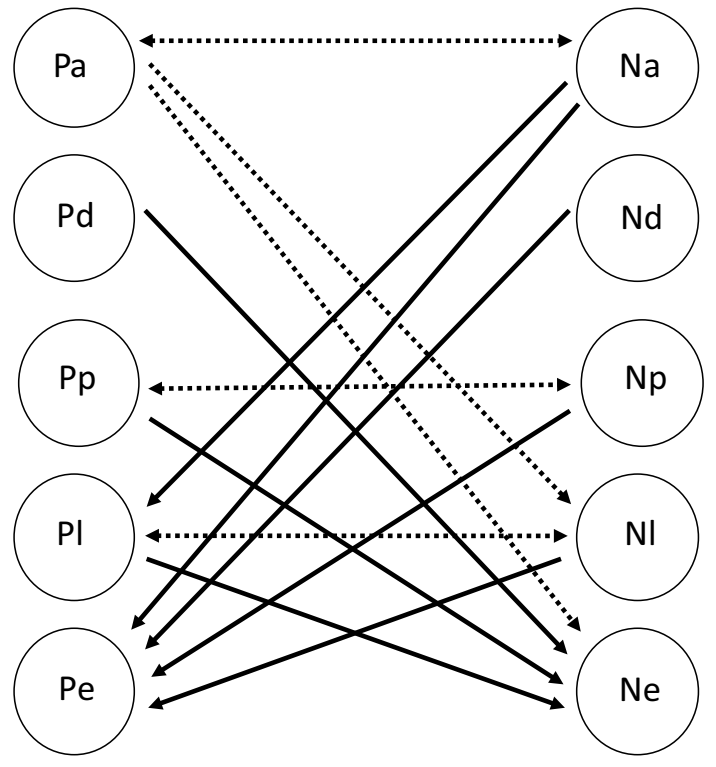

Fig. 5 Intraguild predation among various stages of the predatory mites $P$. macropilis and $N$. californicus. The capital letters in the circles indicate the predator species ("P" for P. macropilis and "N" for $N$. californicus) and the normal type signifies the ontogenetic stages ("a" for adults, "d" for deutonymphs, "p" for protonymphs, "l" for larvae and "e" for eggs). Arrows point from attacker to victim. The solid lines indicate the occurrence of intraguild predation and dashed lines indicate its absence

juveniles of $P$. macropilis develop from larva until adult when feeding on $N$. californicus eggs, the large adult females of P. macropilis did not feed on the smaller stages (eggs and larvae, Fig. 5) of $N$. californicus. It is therefore crucial to investigate IGP by all ontogenetic stages of the species involved. Because IGP is frequently associated with complex life cycles (Polis et al. 1989) and because ontogenetic shifts represent the mode of life in $80 \%$ of animal taxa (Werner 1988), similar phenomena are likely to occur in many other IGP systems. Moreover, this demonstrates the complexity of interactions among stage-structured populations (de Roos and Persson 2013) and the ways in which stage-structured IG predators and IG prey can interact. We furthermore show that IGP in our system was reciprocal (Fig. 5). Although there was no IG predation in the experiments between juveniles of the same stages of both species, and also not between adult females, both juveniles and adult females of $N$. californicus were IG predators of smaller stages of $P$. macropilis.

Besides stage structure, another criterion for assessing the possible occurrence of IGP is that the predation should result in direct nutritional and energetic gains, i.e. increased growth, reproduction or survival (Polis et al. 1989; Fonseca et al. 2017). Here, we show that juveniles of $P$. macropilis, a species considered as a highly specialized predator of Tetranychid mites (McMurtry and Croft
1997), can complete their juvenile development feeding only on IG prey. Neoseiulus californicus was classified as a selective predator of Tetranychids (McMurtry and Croft 1997; Croft et al. 1998), but its juveniles also develop until adulthood feeding only on IG prey, and 50 and $100 \%$ of the adult females reproduced on eggs or larvae of $P$. macropilis, respectively. We therefore suggest that the concept of specialist predatory mites used in the literature may be too strict (McMurtry and Croft 1997). Because many predator-prey systems in nature are ephemeral, organisms will commonly encounter situations without prey and therefore have to adapt to feed on other available resources. Thus, what defines a predator's diet, are the encounter rates with different prey types (Rosenheim et al. 2004) and its ontogenetic stage. In case of IGP, such adaptations to alternative food possibly originate from interference competition because there will probably be selection for those predators that do not only kill their competitors, but also feed on them (Fonseca et al. 2017). Subsequently, selection can act on the IG predators to be more efficient at converting IG prey (Polis 1988; Polis et al. 1989; Fonseca et al. 2017).

Considering a three-species module (an IG predator, an IG prey and a shared prey), IGP may in theory result in the exclusion of one of the predator species (Diehl and Feissel $2000,2001)$. For coexistence of all three species, the IG prey must be superior at exploitative competition for the shared resource, and even then coexistence is only possible at intermediate levels of productivity (Polis and Holt 1992; Holt and Polis 1997; Mylius et al. 2001). Nevertheless, IGP is thought to be ubiquitous in nature (Polis et al. 1989; Arim and Marquet 2004), and several ecological factors such as structural complexity of the habitat (Finke and Denno 2002; Warfe and Barmuta 2004; Harvey and Eubanks 2005; Griffen and Byers 2006; Janssen et al. 2007; but see Reichstein et al. 2013) and the presence of alternative resources (Holt and Huxel 2007; Daugherty et al. 2007) can increase the possibilities for coexistence. Several theoretical and empirical studies have shown that coexistence of IGP predators and prey may sometimes be enhanced by stage structure (Mylius et al. 2001; Borer 2002; Hin et al. 2011; Schellekens and van Kooten 2012). However, other experimental and theoretical studies demonstrated that the stage structure of species involved in IGP reduced the scope of coexistence (van de Wolfshaar et al. 2006; Persson et al. 2007b; Montserrat et al. 2008, 2012; Schröder et al. 2009; Reichstein et al. 2013; Toscano et al. 2016). In conclusion, it is clear that stage structure does affect the dynamics and persistence of populations involved in intraguild predation, not in the least because it can lead to reciprocal IGP. We therefore suggest that models of IGP could include more complex stage structure, and empirical studies should consider the interactions among all stages of interacting species. 
There is growing awareness that ontogenetic shifts among trophic levels may have profound effects on the structure and dynamics of food webs because they result in size- or age-structured interactions (Polis 1984; Cohen et al. 1993a, b; Woodward et al. 2005; Rudolf 2006, 2007; Rudolf and Lafferty 2011; de Roos and Persson 2013). Yet, community matrices often represent networks of feeding links among species (Pimm et al. 1991; De Ruiter et al. 2005; Jonsson et al. 2005), but not among stages of species, and these stages may have different ecological roles with respect to a particular other species. Because the large majority of animal populations are stage, age, or size structured (Werner 1988; de Roos and Persson 2013), we suggest that feeding links in community matrices should be represented at levels lower than the species (see Preston et al. 2012, 2014). Although scientists strive for generalizations and simplifications, and with good reasons, we should always be aware of the intrinsic complexity of natural ecosystems and interactions (Botkin 1990; Meyer 1993). If we would have studied intraguild predation of only adults on juveniles instead of the interactions among various stages of the two predators, we would have concluded that the two species were involved in simple intraguild predation instead of reciprocal IGP. Thus, our results show that interactions among all stages of species with complex life cycles should be studied to increase our understanding of community dynamics.

Acknowledgements We thank Econtrole Pesquisa \& Consultoria Ltda, Aline Francêz and Igor Gomes for support with the rearing of arthropods and plants and the colleagues from the Laboratory of Acarology of the Federal University of Viçosa for suggestions on experimental design and discussion of the results. The constructive comments of the two anonymous reviewers were highly appreciated. MMF was supported by a Ph.D. Grant (151777/2013-6) from the National Council of Scientific and Technological Development (CNPq-Brazil), AP by $\mathrm{CNPq}$ and Foundation for Research Support of the State of Minas Gerais (FAPEMIG-Brazil), EL by the National Institute of Science and Technology (INCT-Brazil) Semiochemicals in Agriculture (CNPq Process 465511/2014-7 and FAPESP Process 2014/50871-0) and AJ by FAPEMIG (CBB-3000309). The experiments comply with the current laws of the country in which the experiments were performed. The authors declare no conflict of interest.

Author contribution statement $\mathrm{MMF}$ and $\mathrm{AJ}$ conceived the ideas and designed the methodology; MMF collected the data; MMF and AJ analysed the data; MMF and AJ led the writing of the manuscript, with contributions of AP and EL. All authors contributed critically to the drafts and gave final approval for publication.

Open Access This article is distributed under the terms of the Creative Commons Attribution 4.0 International License (http://creativeco mmons.org/licenses/by/4.0/), which permits unrestricted use, distribution, and reproduction in any medium, provided you give appropriate credit to the original author(s) and the source, provide a link to the Creative Commons license, and indicate if changes were made.

\section{References}

Aoki S, Kurosu U, Usuba S (1984) First instar larvae of the sugar-cane wooly aphid, Ceratovacuna lanigera (Homotera, Pemphigidae), attack its predators. Kontyû 52:458-460

Arim M, Marquet PA (2004) Intraguild predation: a widespread interaction related to species biology. Ecol Lett 7:557-564

Bakker FM, Sabelis MW (1989) How larvae of Thrips tabaci reduce the attack success of phytoseiid predators. Entomol Exp Appl $50: 47-51$

Belliure B, Janssen A, Sabelis MW (2008) Herbivore benefits from vectoring plant virus through reduction of period of vulnerability to predation. Oecologia 156:797-806

Borer ET (2002) Intraguild predation in larval parasitoids: implications for coexistence. J Anim Ecol 71:957-965

Botkin DB (1990) Discordant harmonies: a new ecology for the twenty-first century. Oxford University Press, New York

Cakmak I, Janssen A, Sabelis MW (2006) Intraguild interactions between the predatory mites Neoseiulus californicus and Phytoseiulus persimilis. Exp Appl Acarol 38:33-46

Choh Y, Ignacio M, Sabelis MW, Janssen A (2012) Predator-prey role reversals, juvenile experience and adult antipredator behaviour. Sci Rep 2(728): 1-6

Cohen JE, Beaver RA, Cousins SH et al (1993a) Improving food webs. Ecology 74:252-258

Cohen JE, Pimm SL, Yodzis P, Saldaña J (1993b) Body sizes of animal predators and animal prey in food webs. J Anim Ecol 62:67-78

Croft B, Monetti L, Pratt P (1998) Comparative life histories and predation types: are Neoseiulus californicus and N. fallacis (Acari: Phytoseiidae) similar type II selective predators of spider mites? Environ Entomol 27:531-538

Daugherty MP, Harmon JP, Briggs CJ (2007) Trophic supplements to intraguild predation. Oikos 116:662-677

de Almeida AA, Janssen A (2013) Juvenile prey induce antipredator behaviour in adult predators. Exp Appl Acarol 59:275-282

de Roos AM, Persson L (2013) Population and community ecology of ontogenetic development. Princeton University Press, Princeton

De Ruiter PC, Wolters V, Moore JC (2005) Dynamic food webs: multispecies assemblages, ecosystem development and environmental change. Academic Press, San Diego

Diehl S, Feissel M (2000) Effects of enrichment on three-level food chains with omnivory. Am Nat 155:200-218

Diehl S, Feissel M (2001) Intraguild prey suffer from enrichment of their resources: a microcosm experiment with ciliates. Ecology 82:2977-2983

Ehler LE (1996) Structure and impact of natural-enemy guilds in biological control of insect pests. In: Polis GA, Winemiller KO (eds) Food webs: integration of patterns and dynamics. Chapman and Hall, New York, pp 337-342

Elgar MA, Crespi BJ (1992) Cannibalism. Ecology and evolution among diverse taxa. Oxford University Press, New York

Escudero L, Ferragut F (2005) Life-history of predatory mites Neoseiulus californicus and Phytoseiulus persimilis(Acari: Phytoseiidae) on four spider mite species as prey, with special reference to Tetranychus evansi (Acari: Tetranychidae). Biol Contr 32:378-384

Faraji F, Janssen A, Sabelis MW (2001) Predatory mites avoid ovipositing near counterattacking prey. Exp Appl Acarol 25:613-623

Ferla NJ, Marchetti MM, Gonçalves D (2007) Ácaros predadores (Acari) associados à cultura do morango (Fragaria sp., Rosaceae) e plantas próximas no Estado do Rio Grande do Sul. Biota Neotrop 7:1-8

Finke DL, Denno RF (2002) Intraguild predation diminished in complex-structured vegetation: implications for prey suppression. Ecology 83:643-652 
Fonseca MM, Montserrat M, Guzmán C et al (2017) How to evaluate the potential occurrence of intraguild predation. Exp Appl Acarol 72:103-114

Gerson U, Smiley RL, Ochoa R (2003) Mites (Acari) for pest control. Blackwell, Oxford, UK

Griffen BD, Byers JE (2006) Partitioning mechanisms of predator interference in different habitats. Oecologia 146:608-614

Guo Y, Lv J, Jiang X et al (2016) Intraguild predation between Amblyseius swirskii and two native Chinese predatory mite species and their development on intraguild prey. Sci Rep 6:22992

Harvey CT, Eubanks MD (2005) Intraguild predation of parasitoids by Solenopsis invicta: a non-disruptive interaction. Entomol Exp Appl 114:127-135

Hin V, Schellekens T, Persson L, de Roos AM (2011) Coexistence of predator and prey in intraguild predation systems with ontogenetic niche shifts. Am Nat 178:701-714

Holt RD, Huxel GR (2007) Alternative prey and the dynamics of intraguild predation: theoretical perspectives. Ecology 88:2706-2712

Holt RD, Polis GA (1997) A theoretical framework for intraguild predation. Am Nat 149:745-764

Janssen A, Pallini A, Venzon M, Sabelis MW (1998) Behaviour and indirect interactions in food webs of plant- inhabiting arthropods. Exp Appl Acarol 22:497-521

Janssen A, Faraji F, van der Hammen T et al (2002) Interspecific infanticide deters predators. Ecol Lett 5:490-494

Janssen A, Willemse E, van der Hammen T (2003) Poor host plant quality causes omnivore to consume predator eggs. J Anim Ecol $72: 478-483$

Janssen A, Montserrat M, HilleRisLambers R et al (2006) Intraguild predation usually does not disrupt biological control. In: Brodeur J, Boivin G (eds) Trophic and guild interactions in biological control. Springer, Dordrecht, pp 21-44

Janssen A, Sabelis MW, Magalhães S et al (2007) Habitat structure affects intraguild predation. Ecology 88:2713-2719

Jonsson T, Cohen JE, Carpenter SR (2005) Food webs, body size, and species abundance in ecological community description. Adv Ecol Res 36:1-84

Marques RV, Sarmento RA, Oliveira AG et al (2018) Reciprocal intraguild predation and predator coexistence. Ecol Evol 8:6952-6964

McMurtry JA, Croft BA (1997) Life-styles of phytoseiid mites and their role in biological control. Annu Rev Entomol 42:291-321

Messelink GJ, Janssen A (2014) Increased control of thrips and aphids in greenhouses with two species of generalist predatory bugs involved in intraguild predation. Biol Contr 79:1-7

Messelink G, Sabelis MW, Janssen A (2012) Generalist predators, food web complexities and biological pest control in greenhouse crops. In: Larramendy ML, Soloneski S (eds) Integrated pest management and pest control—current and future tactics. InTech, Rijeka, pp 191-214

Meyer JL (1993) The dance of nature: new concepts in ecology. ChiKent L Rev 69:875

Migeon A, Dorkeld F (2015) Spider mites web: a comprehensive database for the Tetranychidae. http://www.montpellier.inra.fr/CBGP/ spmweb. Accessed 21 May 2017

Montserrat M, Magalhaes S, Sabelis MW et al (2008) Patterns of exclusion in an intraguild predator-prey system depend on initial conditions. J Anim Ecol 77:624-630

Montserrat M, Magalhaes S, Sabelis MW et al (2012) Invasion success in communities with reciprocal intraguild predation depends on the stage structure of the resident population. Oikos 121:67-76

Mylius SD, Klumpers K, de Roos AM, Persson L (2001) Impact of intraguild predation and stage structure on simple communities along a productivity gradient. Am Nat 158:259-276
Oliveira H, Janssen A, Pallini A et al (2007) A phytoseiid predator from the tropics as potential biological control agent for the spider mite Tetranychus urticae Koch (Acari: Tetranychidae). Biol Contr 42:105-109

Palomares F, Caro TM (1999) Interspecific killing among mammalian carnivores. Am Nat 153:492-508

Persson L, Amundsen PA, De Roos AM et al (2007a) Culling prey promotes predator recovery-alternative states in a whole-lake experiment. Science 316:1743-1746

Persson L, De Roos AM, Byström P (2007b) State-dependent invasion windows for prey in size-structured predator-prey systems: whole lake experiments. J Anim Ecol 76:94-104

Pimm SL, Lawton JH, Cohen JE (1991) Food web patterns and their consequences. Nature 350:669-674

Polis GA (1984) Age structure component of niche width and intraspecific resource partitioning: can age groups function as ecological species? Am Nat 123:541-564

Polis G (1988) Exploitation competition and the evolution of interference, cannibalism, and intraguild predation in age/size-structured populations. In: Ebenman B, Persson L (eds) size-structured populations. Springer, Berlin, Heidelberg, pp 185-202

Polis GA (1991) Complex trophic interactions in deserts: an empirical critique of food-web theory. Am Nat 138:123-155

Polis GA, Holt RD (1992) Intraguild predation-the dynamics of complex trophic interactions. TREE 7:151-154

Polis GA, Strong DR (1996) Food web complexity and community dynamics. Am Nat 147:813-846

Polis GA, Myers CA, Holt RD (1989) The ecology and evolution of intraguild predation - potential competitors that eat each other. Annu Rev Ecol Syst 20:297-330

Preston DL, Orlofske SA, McLaughlin JP, Johnson PTJ (2012) Food web including infectious agents for a California freshwater pond. Ecology 93:1760

Preston DL, Jacobs AZ, Orlofske SA, Johnson PTJ (2014) Complex life cycles in a pond food web: effects of life stage structure and parasites on network properties, trophic positions and the fit of a probabilistic niche model. Oecologia 174:953-965

R Development Core Team (2017) R: a language and environment for statistical computing. R Foundation for Statistical Computing, Vienna

Reichstein B, Schroder A, Persson L, de Roos AM (2013) Habitat complexity does not promote coexistence in a size-structured intraguild predation system. J Anim Ecol 82:55-63

Roggia S, Guedes JVC, Kuss-Roggia RCR et al (2009) Ácaros predadores e o fungo Neozygites floridana associados a tetraniquídeos em soja no Rio Grande do Sul. Pesquisa Agropecuária Brasileira 44:107-110

Rosenheim JA (1998) Higher-order predators and the regulation of insect herbivore populations. Annu Rev Entomol 43:421-447

Rosenheim JA, Wilhoit LR, Armer CA (1993) Influence of intraguild predation among generalist insect predators on the suppression of an herbivore population. Oecologia 96:439-449

Rosenheim JA, Kaya HK, Ehler LE et al (1995) Intraguild predation among biological control agents - theory and evidence. Biol Contr 5:303-335

Rosenheim JA, Limburg DD, Colfer RG (1999) Impact of generalist predators on a biological control agent, Chrysoperla carnea: direct observations. Ecol Appl 9:409-417

Rosenheim JA, Limburg DD, Colfer RG et al (2004) Herbivore population suppression by an intermediate predator, Phytoseiulus macropilis, is insensitive to the presence of an intraguild predator: an advantage of small body size? Oecologia 140:577-585

Rudolf VHW (2006) The influence of size-specific indirect interactions in predator-prey systems. Ecology 87:362-371 
Rudolf VH (2007) Consequences of stage-structured predators: cannibalism, behavioral effects, and trophic cascades. Ecology 88:2991-3003

Rudolf V, Lafferty KD (2011) Stage structure alters how complexity affects stability of ecological networks. Ecol Lett 14:75-79

Saito Y (1986) Prey kills predator: counter attack success of a spider mite against its specific phytoseiid predator. Exp Appl Acarol 2:47-62

Schellekens T, van Kooten T (2012) Coexistence of two stage-structured intraguild predators. J Theor Biol 308:36-44

Schröder A, Nilsson KA, Persson L et al (2009) Invasion success depends on invader body size in a size-structured mixed predation-competition community. J Anim Ecol 78:1152-1162

Souza-Pimentel G, Reis P, Bonatto C et al (2017) Reproductive parameters of Phytoseiulus macropilis (Banks) fed with Tetranychus urticae Koch (Acari: Phytoseiidae, Tetranychidae) in laboratory. Braz J Biol 77:162-169

Toscano BJ, Rombado BR, Rudolf VHW (2016) Deadly competition and life-saving predation: the potential for alternative stable states in a stage-structured predator-prey system. Proc R Soc B 283:20161546

Toscano BJ, Hin V, Rudolf VH (2017) Cannibalism and intraguild predation community dynamics: coexistence, competitive exclusion, and the loss of alternative stable states. Am Nat 190:617-630

van de Wolfshaar KE, de Roos AM, Persson L (2006) Size-dependent interactions inhibit coexistence in intraguild predation systems with life-history omnivory. Am Nat 168:62-75

Van Leeuwen A, De Roos A, Persson L (2008) How cod shapes its world. J Sea Res 60:89-104

Van Leeuwen T, Vontas J, Tsagkarakou A et al (2010) Acaricide resistance mechanisms in the two-spotted spider mite Tetranychus urticae and other important Acari: a review. Insect Biochem Mol Biol 40:563-572

van Lenteren JC, Bolckmans K, Köhl J et al (2018) Biological control using invertebrates and microorganisms: plenty of new opportunities. Biocontrol 63:39-59

Warfe DM, Barmuta LA (2004) Habitat structural complexity mediates the foraging success of multiple predator species. Oecologia 141:171-178

Wells PM, Baverstock J, Clark SJ et al (2017) Determining the effects of life stage, shared prey density and host plant on intraguild predation of a native lacewing (Chrysoperla carnea) by an invasive coccinellid (Harmonia axyridis). Biocontrol 62:373-384

Werner E (1988) Size, scaling, and the evolution of complex life cycles. In: Ebenman B, Persson L (eds) Size-structured populations: ecology and evolution. Springer, Berlin Heidelberg, pp 60-81

Werner EE, Gilliam JF (1984) The ontogenetic niche and species interactions in size-structured populations. Annu Rev Ecol Syst 15:393-425

Wilbur H (1988) Interactions between growing predators and growing prey. In: Ebenman B, Persson L (eds) Size-structured populations: ecology and evolution. Springer, Berlin Heidelberg, pp 157-172

Wissinger SA (1992) Niche overlap and the potential for competition and intraguild predation between size-structured populations. Ecology 73:1431-1444

Woodward G, Hildrew AG (2002) Body-size determinants of niche overlap and intraguild predation within a complex food web. J Anim Ecol 71:1063-1074

Woodward G, Speirs DC, Hildrew AG (2005) Quantification and resolution of a complex, size-structured food web. Adv Ecol Res $36: 85-135$ 